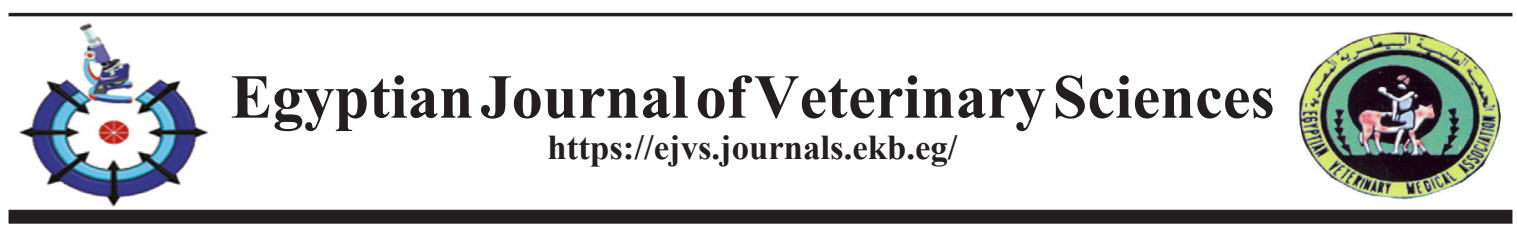

\title{
Bakers' yeast Induced Paw Edema and Fever in Chicks for Detection of Anti-inflammatory Effects of Alpha-lipoic Acid: A new Approach
}

\author{
M. R. Abdul-Gani ${ }^{1}$ and A. S. Naser ${ }^{2}$ \\ ${ }^{1}$ Department of Physiology, Biochemistry and Pharmacology, Faculty of Veterinary \\ Medicine, University of Mosul, Mosul, Iraq. \\ ${ }^{2 *}$ Department of Physiology, Biochemistry and Pharmacology, Faculty of Veterinary \\ Medicine, University of Mosul, Mosul, Iraq.
}

\begin{abstract}
B ackground: Alpha-lipoic acid (ALA) is an antioxidant and anti-inflammatory agent. Baker's yeast produced a fever model that consider a pyrogenic agent. Objective: The goal of this research was to assess the influence of ALA on the inflammation induced by bakers' yeast as edema and fever. Methods: Bakers' yeast was used to induce fever and swelling in the palm area of the right foot of broiler chicks, then we measure the thickness of the edema and body temperature at different times. Results: Bakers' yeast at a concentration of $270 \mathrm{mg} / 5$ $\mathrm{ml}$ into the right palm of the feet of the chicks induce fever and edema after 4 hours. ALA at $75,150 \mathrm{and} 300 \mathrm{mg} / \mathrm{kg}$ intraperitoneally causes a reduction in the thickness of the feet in a dose and time-dependent manner, furthermore, ALA at 75,150and $300 \mathrm{mg} / \mathrm{kg}$ intraperitoneally reduce body temperature in a dose and time-dependent manner.

Conclusion: As a consequence, this study describes a new induced paw edema model that is not only advantageous from an economic viewpoint, but also from a technical perspective. Furthermore, ALA has preemptive anti-inflammatory and antipyretic properties in broiler chicks.
\end{abstract}

Keywords: Baker's yeast, Edema, Fever, Alpha lipoic acid.

\section{Introduction}

The yeast species Saccharomyces cerevisiae is the source of Baker's yeast which is derivative from it. Baker's yeast was commonly utilized as a pyrogenic agent from fungal sources for inducing hyperpyrexia in research studies assessing antipyretics[1] in animals model like rats[2], mice[3], rabbits[4] and birds[5].

Baker's yeast and Brewer's yeast triggers pyrexia, fatigue and loss of appetite that was followed by increased concentration of inflammatory cytokines like interleukin- 6 and tumor necrosis factor- $\alpha$ in the blood plasma and stimulation of inflammatory transcription factors (nuclear factor for stimulator of transcription
STAT-3), and NF- $\mathrm{B}$ )) and interleukin-6,the signal transducer in the hypothalamic tissue and other organs[2]. Increased transcription factor activation after yeast administration was associated with enhanced hypothalamic mRNA expression of TNF $\alpha$, IL-1, and IL-6, as well as ratelimiting enzymes for prostaglandin creation[2]. The paw edema method is a reliable method for assessment the anti-inflammatory properties of remedies[6]. Formalin, lipopolysaccharide, carrageenan, zymosan and arachidonic acid were used previously to induce paw edema in animal's model. Formalin after injection produce 2 phases, phase one result from chemical stimulation to the pain receptor showing acute pain then after 15-20 minutes phase 2 starts which is characterized by

Corresponding authors: A.S.Naser, Email: ahmadphd0@gmail.com, Tel. +9647702012166

(Received 21/11/2021; accepted 13/01/2022)

DOI. 10.21608/ejvs.2022.107080.1314

(C)2022 National Information and Documentation Centre (NIDOC) 
accumulation of fluid at the site of injection and edema development [7]. Lipopolysaccharide LPS is an ideal activator of inflammatory cytokines, LPS-induced edema may be due to enhanced expression of TNF- $\alpha$ and IL-1h, IL-6[8]. Zymosan is a wall constituent of the yeast Saccharomyces cerevisiae that yields an extreme inflammatory reaction, Plasma treatment with zymosan is recognized to stimulate complement and create Csa, a powerful chemotactic agent for neutrophils [9]. Carrageenan a polysaccharide from the seaweed-Rhodophycae, has been characterized by a primary phase began by the histamine, serotonin and bradykinin release, continued by a secondary phase mainly followed by releasing of prostaglandin, While Carrageenan stimulates expression of only IL-1h. Chemical mediators like histamine,5HT and prostaglandins play a crucial role in Carrageenan -induced edema[10]

Many studies have described ALA as antioxidant and anti-inflammatory agent, because it has a very high defense mechanism against free radicals in various ways[11,12]. Later work has shown that ALA can be used to prevent or treat a variety of pathological conditions caused by oxidative stress. ALA has been shown to inhibit the release of several cytokines, such as tumor necrosis factor alpha $(\mathrm{TNF} \alpha)$ and interleukin 6 . (IL6) [13].

While numerous facts on the capability of ALA to increase immune ability and antioxidant defenses and suppress inflammatory reactions are existing, it is unclear yet if ALA can also reverse the inflammatory state caused by baker yeast in broiler chicks. In this study, we examined the effects of baker's yeast as paw edema inducible and assess the anti-inflammatory and antipyretic properties of ALA in broiler chicks.

\section{Materials and Methods}

\section{Materials}

Baker's yeast (Saf-instant ${ }^{\circledR}$ Red yeast) was used to induce paw edema at $270 \mathrm{mg} / \mathrm{kg}$ dose was dissolved in $5 \mathrm{ml}$ distilled water, ALA (Lipoic-Forte by $\mathrm{AMS}^{\circledR}$ ), was dissolved in propylene glycol at different doses to evaluate the anti-inflammatory effects. Digital caliper to determine the thickness of paw edema and digital thermometer to determine the core body temperature was used in our experiment.

\section{Animals}

Ross broiler chicks of both sexes were obtained at age of one day from a local hatchery in Nineveh,
Iraq. This is an appropriate lab animal (chick) model used previously in pharmacological and toxicological studies[14,15]. They were housed in batches of 20-25 chicks at a temperature of 25-30 ${ }^{\circ} \mathrm{C}$ with constant lighting and wood shavings as floor litter. The water and feed were ad libitum. Experiments were conducted when the ages of the chicks were between 7-9 days and an average of 6 chicks per group.

\section{Baker's yeast-induced foot edema and pyrexia in chicks}

The anti-inflammatory activity of ALA was evaluated using a baker's yeast-induced foot edema model of inflammation in chicks with slight modifications16]. At the first meloxicam $(10 \mathrm{mg} / \mathrm{kg}$ IP) was used as a positive control, Control animals received only propylene glycol, which serves as a negative control. ALA was administered intraperitoneally at different doses $(75,150$, and $300 \mathrm{mg} / \mathrm{kg})$ then one hour after the injection of all groups the Becker>s yeast $(10 \mu \mathrm{l})$ in the paw of the right foot of chicks to induce edema. A digital Caliper was utilized to measure foot volume at administration and at 1, 2, 3, and 4 $\mathrm{h}$ after administration. Simultaneously to measure edema caused by bakers〉 yeast, the Cloacal temperature (TC) was measured by inserting a lubricated digital thermometer 2 centimeters into the cloaca of the chicks. TC was monitored hourly over the next 4 hour period after all groups were administered.

\section{Ethical approval}

We obtained the official approval for the study protocol from the Committee of Postgraduate Studies at the College of Medicine, University of Mosul, Iraq according to institutional regulations on animal handling and use in research.

\section{Statistical analysis}

The statistics software package SPSS (IBM) for statistical analysis of the data was used. Excel2013 program was used for design the figures. Data were evaluated by one and twoway analysis of variance followed by the least significant difference test. Data were expressed as mean + SE (standard error), $\mathrm{p}<0.05$ was considered statistically significant.

\section{Results}

Baker's yeast-induced edema

The time course curves for the impacts of ALA and meloxicam on baker's yeast-induced edema in chicks are shown in Figures 1, 2, 3, 4, and 5. Baker's yeast injection $(10 \mu \mathrm{L}$, ) induced 
remarkable inflammation resulting in foot edema and reddens in the chicks climax at 3-4h (Fig. 1). The two-way ANOVA (treatment and time) demonstrated that treatment had a significant effect on ALA (preemptive) and meloxicam (preemptive). In other words, ALA reduces paw swelling in a dose and time-dependent manner when compared to the negative and positive control groups. The anti-inflammatory activity percentage for Alpha-lipoic acid at 20, 40 and 80 $\mathrm{mg} / \mathrm{kg}$ was 9, 19 and 20 respectively.

\section{Baker's yeast -induced pyrexia}

The time course curves for the effects of ALA and meloxicam on baker's yeast-induced pyrexia in chicks are shown in Table 1 and Fig. 6. Baker's yeast injection $(10 \mu \mathrm{L}$, ) caused significant inflammation in the chicks, resulting in pyrexia that peaked at $4 \mathrm{~h}$ (Fig. 1). The two-way ANOVA

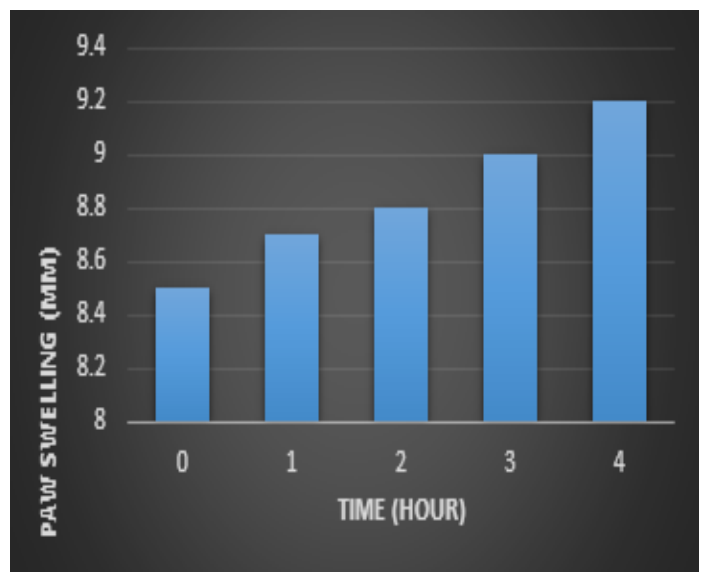

Fig. 1 (control)

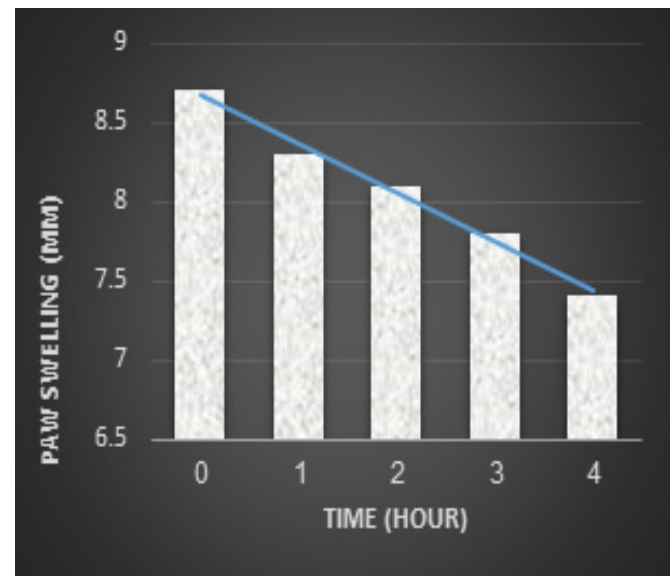

Fig. 3 (ALA75mg) (treatment and time) revealed a significant effect of drug treatment for ALA (preemptive), which means that ALA causes a dose and time dependent reduction in cloacal temperature when compared to the negative control group.

\section{Discussion}

We designate a cheap and dependable technique for developing paw edema and pyrexia in chicks in this study. In features of drug and lab animal testing, the current method of inducing paw edema and pyrexia appears to be superior to last approaches that utilize different pyrogenic materials, as will be discussed in detail below.

In the beginning and first of all, through our study we were able to combine two tests in one test. The fever induction test was conducted alone and the edema induction test was conducted

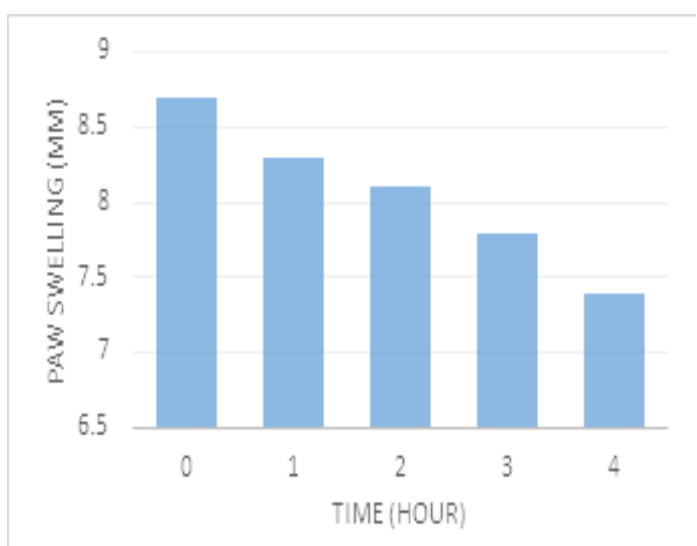

Fig. 2 (meloxicam 10mg)

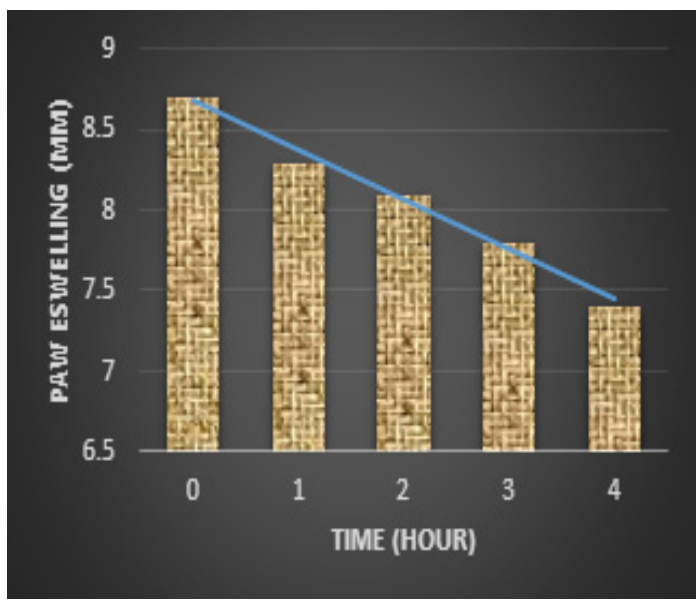

Fig. 4 (ALA 150mg)

Egypt. J. Vet. Sci. Vol. 53, No. 2 (2022) 


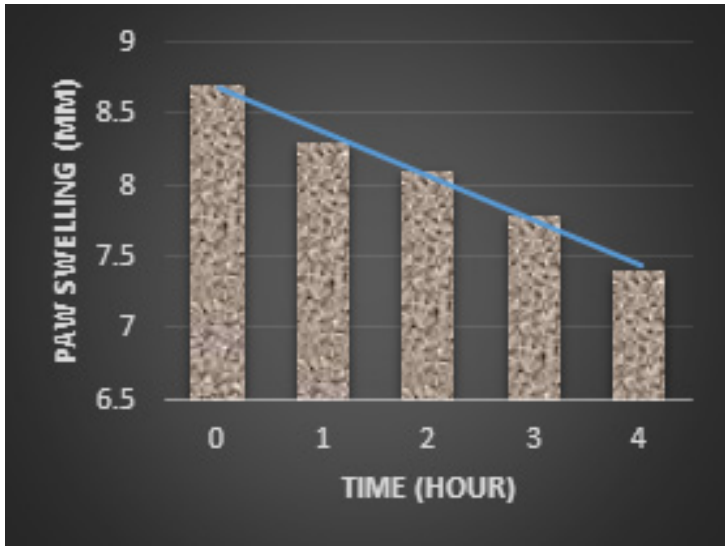

Fig. 5 (ALA 300mg)

TABLE 1. Preemptive antipyretic effect of alpha lipoic acid against pyrexia induced by baker's yeast

\begin{tabular}{lccccc}
\hline Groups & \multicolumn{5}{c}{ Time in hour for determine the Cloacal temperature } \\
\cline { 2 - 6 } & $\mathbf{0}$ & $\mathbf{1}$ & $\mathbf{2}$ & $\mathbf{3}$ & $\mathbf{4}$ \\
\hline propylene glycol & $39.3 \pm 0.07$ & $39.1 \pm 0.08$ & $39.1 \pm 0.06$ & $39.3 \pm 0.09$ & $39.7 \pm 0.13$ \\
Meloxicam 10mg & $39.6 \pm 0.27$ & $40.2 \pm 0.31 *$ & $39.8 \pm 0.15$ & $39.6 \pm 0.17$ & $40.0 \pm 0.18$ \\
ALA 75mg & $39.5 \pm 0.15$ & $37.6 \pm 0.30 * \mathrm{a}$ & $37.7 \pm 0.33 * \mathrm{a}$ & $38.8 \pm 0.19$ & $39.7 \pm 0.19$ \\
ALA 150mg & $39.4 \pm 0.12$ & $37.3 \pm 0.45 * \mathrm{a}$ & $36.8 \pm 0.40 * \mathrm{ab}$ & $37.1 \pm 0.72 * \mathrm{abc}$ & $37.9 \pm 0.60 * \mathrm{abc}$ \\
ALA 300mg & $39.6 \pm 0.21$ & $36.7 \pm 0.48 * \mathrm{a}$ & $35.6 \pm 0.27 * \mathrm{abc}$ & $35.1 \pm 0.30 * \mathrm{abc}$ & $35.3 \pm 0.33 * \mathrm{abc}$ \\
\hline
\end{tabular}

$\mathrm{n}=6$, the observations are mean \pm SEM,

$* \mathrm{P}<0.05$, as compared to propylene glycol group,

a $\mathrm{P}<0.05$, as compared to meloxicam at $10 \mathrm{mg} / \mathrm{kg}$,

b $\mathrm{P}<0.05$, as compared to ALA at $75 \mathrm{mg} / \mathrm{kg}$.

c $\mathrm{P}<0.05$, as compared to ALA at $150 \mathrm{mg} / \mathrm{kg}$.

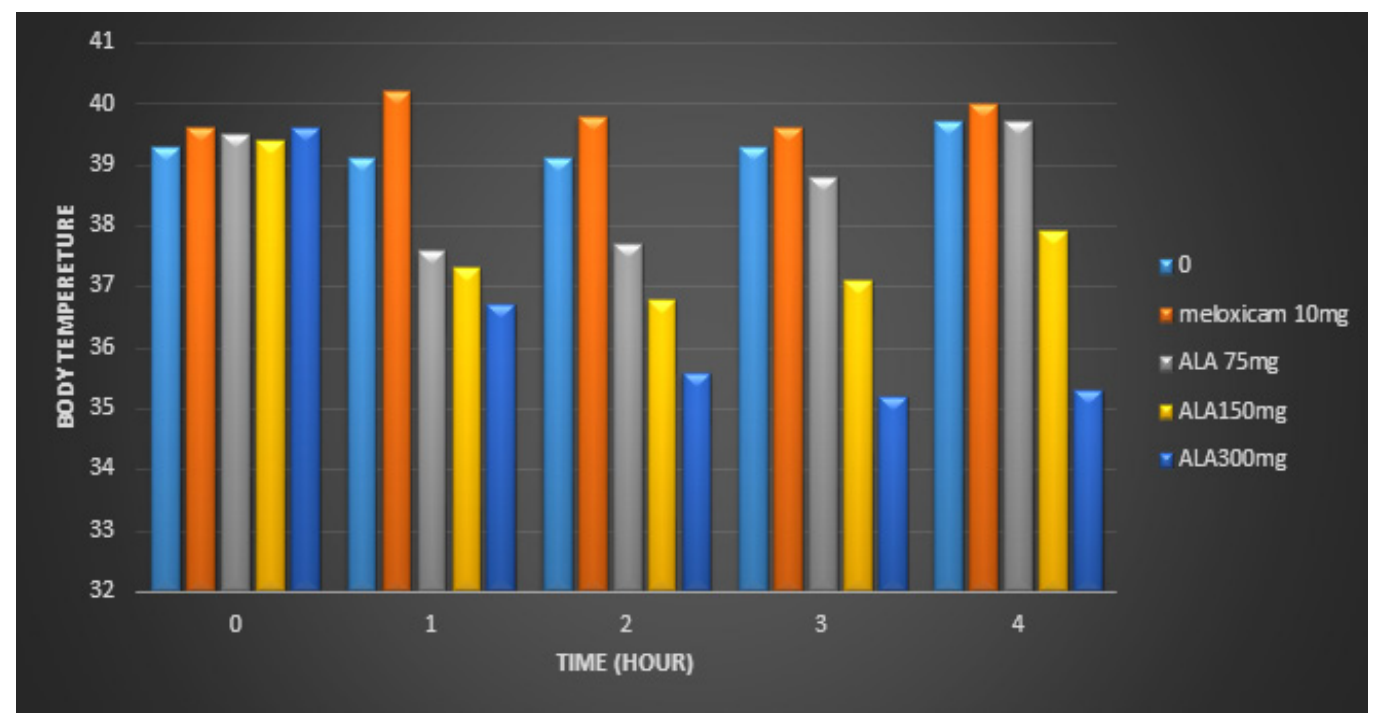

Fig. 6. (Antipyretic effect of ALA to fever Induced by Baker yeast)

Egypt. J. Vet. Sci. Vol. 53, No. 2 (2022) 
alone. Thus, we shortened the time and reduced the experimental animals in the new method that we introduced.

The administration of Baker's yeast subcutaneously after 4 hours into the plantar area of the chick's paws triggered an acute inflammatory state leading to enlargement of the injected paws. Analogous inflammatory states are elicited by other materials, carrageenan[17], zymosan[18] and formalin[19] and have been established to be active in recognizing beneficial anti-inflammatory remedies. Carrageenaninduced edema consequences from the chemical mediators releasing like 5HT and histamine through the 1st hour and prostaglandins through the next $2 \mathrm{~h}$. Zymosan-induced edema is reliant on interlukin-1 mediated inflammation. While, formalin-induced edema is related to bradykinin release [17] .Our study evidently creates the antiinflammatory and antipyretic properties of the Alpha-lipoic acid in chick's model. Our results confirmed the anti-inflammatory effect of alphalipoic acid by reducing the volume of edema in the feet of chicks injected with bakers' yeast. The mechanism of alpha-lipoic acid's antiinflammatory action may be through inhibition of inflammatory cytokines and TNF-alpha or through inhibition of production of inflammatory prostaglandins.

The core body temperature of the chick's injected baker's yeast $(270 \mathrm{mg} / \mathrm{kg})$ initially decreased. The drop in core body heat continued for 2 hours and was accompanied by pyrexia, which climax at 4 hours after injection these findings agree with the study conducted by brewer's yeast on rats' models[1].

Our findings reveal that ALA drops body temperature in feverish chicks. ALA administration has been shown in mammalian species to drop body temperature by enhanced heat loss by panting and cutaneous vasodilation in both cold and hot environments. [20,21] , and we expected the chicks of the current study dropped body temperature by resembling mechanism. If so, then ALA might have brought the loos of heat by its thiol-reducing effect on N- methyl Daspartate receptors in the central nervous system resemble to in the mammals, It may be due to the thiol-induced heat loss responses are overcome by $\mathrm{N}$ - methyl $\mathrm{D}$ - aspartate blockers $[20,22,23]$. ALA must be converted enzymatically to the reduced form dihydrolipoic acid earlier it can be used as a thiol reductant (DHLA). This has been observed in rabbits to occur quickly; moreover, the production of DHLA is significantly reduced in fever[21].

In conclusion, in this article we exist and describe a dependable procedure to induce edema (localized inflammation) and fever (generalized inflammation) in chicks that appears particularly appropriate to assess new drugs. One of the top advantages of the present model is that it allows anti-inflammatory and antipyretic assessment with one procedure. So a significant decrease in the number of animals necessary for each assessment. Therefore, this protocol seems to be not only advantageous from the economic and technical point of vision, but also has more animal ethical concerns. Finally ALA has preemptive anti-inflammatory and antipyretic properties in broiler chicks.

\section{Conflict of interest}

The authors declare that they have no potential conflicts of interest.

\section{Acknowledgments}

The University of Mosul provided the necessary funds and facilities to support the present research which is part of the MSc thesis in Veterinary Pharmacology of the first author.

\section{Funding statement}

The author declares there is no funding in this study.

\section{References}

1. Dangarembizi, R., Erlwanger, K. H., Rummel, C., Roth, J., Madziva, M. T., and Harden, L. $\mathrm{M}$ Brewer's yeast is a potent inducer of fever, sickness behavior and inflammation within the brain. Brain. Behav. Immun., 68, 211-223 (2018).

2. Tomazetti, J., Ávila, D. S., Ferreira, A. P. O., Martins, J. S., Souza, F. R., Royer, C. and Mello, C. F. Baker yeast-induced fever in young rats: characterization and validation of an animal model for antipyretics screening. J. Neurosci. Methods, 147, 29-35 (2005).

3. Bhat, A. S., Tandan, S. K., Kumar, D., Krishna, V. and Prakash, V. R. Interaction between inhibitors of inducible nitric oxide synthase and cyclooxygenase in Brewer's yeast induced pyrexia in mice: an isobolographic study. Eur. $J$. Pharmacol., 5(11), 137-142 (2005). 
4. Ahmad, S., Rehman, T. and Abbasi, W. M. Effects of homoeopathic ultrahigh dilutions of Aconitum napellus on Baker's yeast-induced fever in rabbits. J. Integr. Med., 15, 209-213 (2017).

5. Woode, E., Poku, R. A., Ainooson, G. K., BoakyeGyasi, E., Abotsi, W. K. M., Mensah, T. L. and Amoh-Barimah, A. K. An evaluation of the antiinflammatory, antipyretic and antinociceptive effects of Ficus exasperata (Vahl) leaf extract. $J$ Pharm. Toxicol., 4, 138-151 (2009).

6. Fereidoni, M., Ahmadiani, A., Semnanian, S. and Javan, M. An accurate and simple method for measurement of paw edema. J. Pharmacol. Toxicol. Methods, 43, 11-14 (2000).

7. Wheeler-Aceto, H., Porreca, F. and Cowan, A. The rat paw formalin test: comparison of noxious agents. Pain, 40, 229-238 (1990).

8. Vajja, B. N., Juluri, S., Kumari, M., Kole, L., Chakrabarti, R. and Joshi, V. D. Lipopolysaccharideinduced paw edema model for detection of cytokine modulating anti-inflammatory agents. Int. Immunopharmacol., 4, 901-909 (2004).

9. Cuzzocrea, S., Zingarelli, B., Calapai, G., Nava, F. and Caputi, A. P. Zymosan-activated plasma induces paw oedema by nitric oxide and prostaglandin production. Life Sci., 60, 215-220 (1996).

10. Morris, C. J. Carrageenan-induced paw edema in the rat and mouse. Inflamm. Protoc., 115-121 (2003).

11. Packer, L., Witt, E. H. and Tritschler, H. J. Alphalipoic acid as a biological antioxidant. Free Radic. Biol. Med., 19, 227-250 (1995).

12. Shay, K. P., Moreau, R. F., Smith, E. J., Smith, A. R. and Hagen, T. M. Alpha-lipoic acid as a dietary supplement: molecular mechanisms and therapeutic potential. Biochim. Biophys. Acta (BBA)-General Subj., 1790, 1149-1160 (2009).

13. Wong, A., Dukic-Stefanovic, S., GasicMilenkovic, J., Schinzel, R., Wiesinger, H., Riederer, P. and Münch, G. Anti-inflammatory antioxidants attenuate the expression of inducible nitric oxide synthase mediated by advanced glycation endproducts in murine microglia. Eur. J. Neurosci., 14, 1961-1967 (2001).
14. Alatrushi, Amjed Najem and Naser, A. Evaluation of the Anesthetic Action of Alfaxalone in Chicks and Compared with Alfaxalone/ketamine or Alfaxalone/xylazine. Egypt. J. Vet. Sci., 52, 221228 (2021).

15. Naser, A. S. and Mohammad, F. K. The antioxidant activity of propofol in chicks. Iraqi J. Vet. Sci., 29, 29-34 (2015).

16. Roach, J. T. and Sufka, K. J. Characterization of the chick carrageenan response. Brain Res., 994, 216-225 (2003).

17. Woode, E., Ansah, C., Ainooson, G. K., Abotsi, W. M., Mensah, A. Y. and Duweijua, M. Antiinflammatory and antioxidant properties of the root extract of Carissa edulis (Forsk.) Vahl (Apocynaceae). J. Sci. Technol., 27, 5-15 (2007).

18. Gühring, H., Tegeder, I., Lötsch, J., Pahl, A., Werner, U., Reeh, P. W. and Geisslinger, G. Role of nitric oxide in zymosan induced paw inflammation and thermal hyperalgesia. Inflamm. Res., 50, 8388 (2001).

19. Albadrany, Y. M., Naser, A. S. and Hasan, M. M. Study the analgesic effect of diclofenac and silymarin coadministration in chicks. Iraqi J. Vet. Sci., (2021).

20. Riedel, W. Temperature homeostasis and redox homeostasis. in Thermotherapy for Neoplasia, Inflammation, and Pain, 300-312 (Springer, 2001).

21. Riedel, W., Lang, U., Oetjen, U., Schlapp, U. and Shibata, M. Inhibition of oxygen radical formation by methylene blue, aspirin, or $\alpha$-lipoic acid, prevents bacterial-lipopolysaccharide-induced fever. Mol. Cell. Biochem., 247, 83-94 (2003).

22. Riedel, W. and Maulik, G. Fever: an integrated response of the central nervous system to oxidative stress. in Stress Adaptation, Prophylaxis and Treatment, 125-132 (Springer, 1999).

23. Canini, F., Bréjot, T., d'Aléo, P., Mercier, S. and Bourdon, L. NMDA receptors are involved in dithiothreitol-induced hypothermia. Eur. J. Pharmacol., 426, 179-183 (2001). 


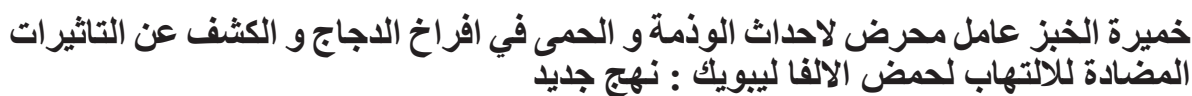

مروى رحاب عبد الغني و احمد صلاح ناصر

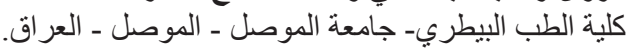

الخلفية العلمية: يعد حمض الالفا ليبويك من اهم مضادات الاكسدة والالتهاب، و قد استخدمت خميرة الخبز

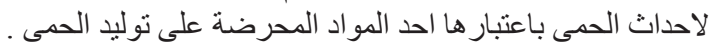

الهُف: كان الهدف من هذا البحث هو تقييم تأثير ALA على الالتهاب الذي تسببه خميرة الخبز كالوذمة و الحمى.

طر ائق العمل: تم استخدام خميرة الخبز للحث على توليد الحمى والانتفاخ في منطقة باطن القدم اليمنى لافر اخ الاجاج ، و بعد ذلك قمنا بقياس سمك الوذمة ودرجة حر ارة الجسم في أوقات مختلفة.

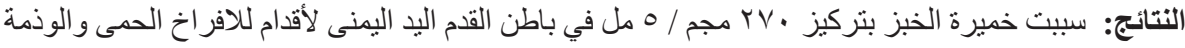

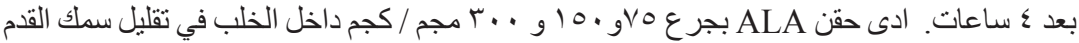

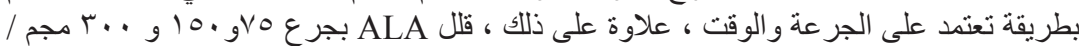

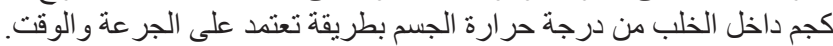

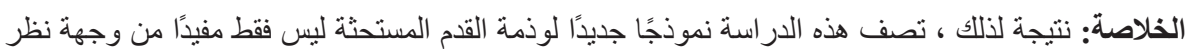

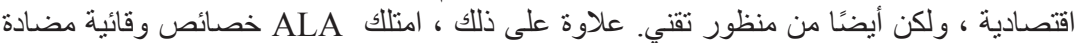

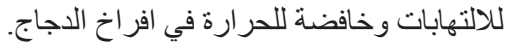

الكلمات الرئيسية: خميرة الخبز ، وذمة ، حمى ، حمض ألفا ليبويك. 